\title{
Structural evolution and electrochemical behaviors of multilayer
}

\author{
Al-Cr-Si-N coatings \\ Mohan Chen, Wanglin Chen, Fei Cai, Shihong Zhang*, Qimin Wang \\ School of Materials Science and Engineering, Anhui University of Technology, Maanshan City, \\ Anhui Province 243002, PR China. \\ *Corresponding author: Tel \& Fax number: +86-555-3553789; Email address: \\ tougaoyouxiang206@163.com
}

Abstract: The corrosion behaviors in $3.5 \% \mathrm{NaCl}$ and $10 \% \mathrm{H}_{2} \mathrm{SO}_{4}$ solutions of the nano-composite $\mathrm{Al}-\mathrm{Cr}-\mathrm{Si}-\mathrm{N}$ coatings, deposited on stainless steel 316L substrates using multi-arc ion plating process, annealed at $700^{\circ} \mathrm{C}, 800^{\circ} \mathrm{C}$ and $900^{\circ} \mathrm{C}$, each for 2 hours, was studied. The phase structures, surface morphologies, adhesion strength, and corrosion properties of the Al-Cr-Si-N coatings before and after vacuum annealing were investigated. Results indicated that, with increasing annealing temperature, the phase structures of the nano-composite $\mathrm{Al}-\mathrm{Cr}-\mathrm{Si}-\mathrm{N}$ coatings varied from solid solution (Cr,Al)N phase to $\mathrm{CrN}, \mathrm{Cr}_{2} \mathrm{~N}$ and $\mathrm{AlN}$ phases with a hexagonal close packed structure (hcp-AlN), and then to $\mathrm{CrN}, \mathrm{Cr}_{2} \mathrm{~N}$, hcp-AlN and $\mathrm{Cr}$ phases, and finally to $\mathrm{CrN}, \mathrm{Cr}_{2} \mathrm{~N}$, hcp-AlN, $\mathrm{Cr}$ and $\sigma$-FeCr phases. The defects on the coating surface were decreased simultaneously. The samples annealed at $800^{\circ} \mathrm{C}$ had the highest adhesion strength. The potentiodynamic polarisation measurements showed that the corrosion resistance of coatings were improved after annealing. The coatings annealed at $800^{\circ} \mathrm{C}$ had the best corrosion resistance in $3.5 \% \mathrm{NaCl}$ solution, and the coatings annealed at $700^{\circ} \mathrm{C}$ had the best corrosion resistance in $10 \% \mathrm{H}_{2} \mathrm{SO}_{4}$ solution. 
Keywords: Multi-arc ion plating; Al-Cr-Si-N coatings; Vacuum annealing; Corrosion resistance 


\section{Introduction}

Nano-composite ceramic coatings, which were prepared by physical vapor deposition (PVD) technology, played an important role in the surface modification of engineering components in various industrial environments owing to their properties such as high hardness[1-3], good tribological properties[4-5], oxidation resistance[6-8] and corrosion resistance[9-11]. However, these coatings exhibited growth-related defects such as micro-cracks, particles and droplets[12-14]. These defects created a direct path between substrate and corrosive media, which would affect the corrosion resistance behavior of these coatings.

To improve the corrosion properties of these PVD coatings, several methods had been used. For example, C. Liu et al.[15] found that the improvement of corrosion resistance was not only attributed to the increase in the coating thickness, but also to the internal microstructure (dense non-columnar structure) and phase composition(mixture of $\alpha-\mathrm{Cr}, \beta-\mathrm{Cr}_{2} \mathrm{~N}, \gamma-\mathrm{CrN}$ phases). M.S. Ahmed et al.[16] reported that the oxide layer formed from coatings surface and reduction of residual stress could increase the corrosion resistance of TiSiN coatings after $900{ }^{\circ} \mathrm{C}$ annealing. In addition, the nano-composite and multilayer structures, incorporation of the interlayer (such as PVD Al, Si etc.)[9,16-19] and alloying of the coatings (i.e. ternary coatings) were helpful to achieve high corrosion resistance by controlling the size and the density of the micro-pores.

The studies on PVD coatings was last for years, but studies on AlCrSiN coatings were limited, and mostly focus on the hardness, tribological properties and oxidation 
resistance[20-23]. Polcar et al.[24] found that AlCrSiN coatings had better oxidation resistance than CrAlN coatings, these coatings also had good tribological properties when temperature blow $500{ }^{\circ} \mathrm{C}$. Zhang et al.[8,20] deposited a superhard CrAlSiN superlattice coatings by multi-arc ion plating(M-AIP), indicated that the coatings exhibited good thermal stability and oxidation resistance when temperature up to $900{ }^{\circ} \mathrm{C}$. The wear test showed that the superhard CrAlSiN coatings has a very low friction coefficient against the counterpart material of WC/Co. Lee et al.[22] also reported that $\mathrm{AlCrSiN}$ coatings exhibited good oxidation resistance between $800{ }^{\circ} \mathrm{C}$ and $1000^{\circ} \mathrm{C}$. But, more remarkable, the research on corrosion resistance of AlCrSiN was more rarer. Lin et al.[25] using electrochemical impedance spectroscopy(EIS), studied corrosion performance of CrAlSiN with different Si content coated steels in 3.5\% $\mathrm{NaCl}$ solution, indicating a significant increase of charge-transferred resistance with increasing Si content. It's worth mentioning that the research on corrosion resistance of AlCrSiN coatings after high temperature annealing is still blank.

In this work, X-ray diffraction(XRD), field emission scanning electron microscopy(FESEM), energy dispersive spectroscopy(EDS) and high resolution transmission electron microscopy(HRTEM) were used to characterize the microstructure evolution. The adhesion strength of coatings were investigated by scratch test combined with Rockwell indentation, and the corrosion behaviors of coatings before and after vacuum annealing were investigated by potentiodynamic polarisation measurements in $3.5 \% \mathrm{NaCl}$ and $10 \% \mathrm{H}_{2} \mathrm{SO}_{4}$ solutions.

\section{Experimental details}




\subsection{Preparation of samples}

The Al-Cr-Si-N coatings investigated in this research were deposited on stainless steel 316L (SS 316L) substrates using M-AIP equipment equipped with 12 sets of standard cathodic arc ion evaporators (three cathode Cr targets(99.9\% purity), three AlCrSi targets (46 at.\% Al, 46 at.\% $\mathrm{Cr}, 8$ at.\% Si, 99.9\% purity) and three $\mathrm{AlCr}$ targets(70 at.\% Al,30 at.\% Cr, 99.9\% purity)). The AlCrSi and AlCr targets were symmetrically installed on the opposite side of the barrel-shaped vacuum chamber wall. The SS 316L substrates ( $3 \mathrm{~mm} \times \Phi 14 \mathrm{~mm}$ ) were polished to an average surface roughness $(\mathrm{Ra} \leq 0.05 \mu \mathrm{m})$ to obtain a mirror-like surface and then ultrasonically cleaned in acetone and alcohol for 15 min, respectively. The substrates were placed into the deposition chamber, with a substrate-target distance of $200 \mathrm{~mm}$, being held by a star-like rotation bracket and rotating at a speed of $4 \mathrm{rpm}$.

Before deposition, the chamber was decreased to a base pressure below $1 \times 10^{-3}$ $\mathrm{Pa}$, the substrates were heated and kept at a temperature of $450{ }^{\circ} \mathrm{C}$, and then the samples were first cleaned by Ar ions bombardment (Ar, 99.99\% purity, flow rate of $80 \mathrm{sccm}$ ) at bias voltage of $-1000 \mathrm{~V}$ for $30 \mathrm{~min}$. The next step was to deposit $\mathrm{CrN}$ and $\mathrm{Al}-\mathrm{Cr}-\mathrm{N}$ interlayers to improve adhesion strength and reduce stress in the interface. At last, the Al-Cr-Si-N coatings were deposited using the AlCrSi targets and AlCr targets, simultaneously. All the deposition process were carried out in $\mathrm{N}_{2}$, and the detailed depositional parameters of each layer had been summarized in Table 1. After deposition, the samples were annealed at temperatures of $700{ }^{\circ} \mathrm{C}, 800{ }^{\circ} \mathrm{C}$ and $900{ }^{\circ} \mathrm{C}$ for 2 hours conducted in a vacuum annealing furnace with a heating rate of $10^{\circ} \mathrm{C} / \mathrm{min}$, 
separately. The base vacuum degree of the furnace was $3.0 \times 10^{-2} \mathrm{~Pa}$. After annealing, the samples were cooled to room temperature in vacuum before being removed from the furnace to prevent oxidation.

\subsection{Properties tests}

The corrosion behaviours of the Al-Cr-Si-N coatings before and after annealing was investigated by potentiodynamic polarisation measurements with a conventional three-electrode cell, in which, sample used as the working electrode was placed in Teflon sample holder and the exposed surface area to the corrosive medium was approximately $1 \mathrm{~cm}^{2}$. The platinum strip of $1 \mathrm{~cm}^{2}$ area served as the counter electrode and a saturated calomel electrode (SCE) as a reference electrode was used. The corrosion measurements were carried out in $3.5 \% \mathrm{NaCl}$ solution and $10 \% \mathrm{H}_{2} \mathrm{SO}_{4}$ solution respectively at room temperature, non-stirred and free air conditions. Potentiodynamic polarisation measurements were performed using the CHI604D system. To establish a steady state potential, the sample was immersed in the solution for 1 hour. The polarisation curves were obtained with a scan rate of $1 \mathrm{mV} / \mathrm{s}$. The corrosion potential $\left(\boldsymbol{E}_{\text {corr }}\right)$ and the corrosion current density $\left(\boldsymbol{i}_{\text {corr }}\right)$ were deduced from the Tafel plots.

\subsection{Characterization}

The adhesion strength of samples before and after annealing was measured by a scratch tester(HT-3001 scratch tester equipped with an acoustic emission detector) 
combined with Rockwell indentation. X-ray diffraction (XRD, BrukerD8 Advance) with a wavelength of $0.15406 \mathrm{~nm} \mathrm{Cu}-\mathrm{K} \alpha$ radiation was used for analyzing the crystallographic phase transformations in the coatings before and after annealing. The scans were recorded in a range from $30^{\circ}$ to $90^{\circ}$ with a step width of $0.02^{\circ}$ at $3^{\circ} / \mathrm{min}$. The microstructure of the coatings were investigated by high resolution transmission electron microscopy (HRTEM, FEI-F20), and samples for TEM were prepared using a dual-beam focus ion beam (FIB) microscope. Surface morphologies and chemical compositions of the coatings were observed using a field emission scanning electron microscopy (FESEM, FEI-NANOSEM 430) with energy dispersive spectroscopy (EDS) for elemental analysis.

\section{Results and discussion}

\subsection{Phase evolution}

The XRD diffraction patterns of as-deposited Al-Cr-Si-N coatings and the coatings vacuum annealed at $700{ }^{\circ} \mathrm{C}, 800{ }^{\circ} \mathrm{C}$ and $900{ }^{\circ} \mathrm{C}$ are shown in Fig. 1 . The annealing temperature strongly affected the structures of $\mathrm{Al}-\mathrm{Cr}-\mathrm{Si}-\mathrm{N}$ coatings. The diffraction peaks of the as-deposited Al-Cr-Si-N coatings located at $37.62^{\circ}$ and $63.71^{\circ}$ were $\mathrm{CrN}$ phases, which were shifted toward to higher angles compared with standard PDF cards. This reflected the formation of (Cr, Al)N solid solution phases, where $\mathrm{Cr}$ atoms was replaced by $\mathrm{Al}$ atoms in the $\mathrm{CrN}$ lattice. After $700{ }^{\circ} \mathrm{C}$ vacuum annealing, the coatings were mainly composed of AlN with hexagonal closepacked structure (hcp-AlN) and $\mathrm{Cr}_{2} \mathrm{~N}$ phases, which indicated that the (Cr, $\left.\mathrm{Al}\right) \mathrm{N}$ solid 
solution were decomposed at $700{ }^{\circ} \mathrm{C}$. When the annealing temperature reached $800{ }^{\circ} \mathrm{C}$, the $(\mathrm{Cr}, \mathrm{Al}) \mathrm{N}$ solid solution phases were further decomposed and some pure $\alpha$-Cr crystalline phases diffraction peaks were detected, which implied $\mathrm{Cr}_{2} \mathrm{~N}$ decomposes to $\alpha$-Cr phases and $N_{2}$. H. Willmann et.al[26] and Pang et.al[27] also found that the $\mathrm{Cr}_{2} \mathrm{~N}$ decomposition resulted in $\alpha$-Cr at high annealing temperatures. Then the annealing temperature further increased to $900{ }^{\circ} \mathrm{C}$, results in much stronger intensities of the hcp-AlN, $\mathrm{Cr}_{2} \mathrm{~N}$ and $\alpha$-Cr phases contrasted with the results at annealing temperature of $700{ }^{\circ} \mathrm{C}$ and $800{ }^{\circ} \mathrm{C}$. Additionally, new diffraction peaks of б-FeCr phases were observed, which indicated some iron atoms from substrates diffused to the coatings, combined with chromium atoms then formed FeCr solid solutions. The diffraction peaks of $\sigma$-FeCr phases, of SS 316L annealed at $900{ }^{\circ} \mathrm{C}$ were not found in Fig. 1, it can be concluded that the $\sigma$-FeCr phases formed from coatings rather than the substrates during vacuum annealing.

Fig. 2 shows the transmission electron microscopy(TEM) micrographs of as-deposited Al-Cr-Si-N coatings. Fig. 2a is the cross-sectional morphologies of the coatings, in which, the thickness of coatings was about $3.3 \mu \mathrm{m}$. The as-deposited Al-Cr-Si-N coatings exhibited a fine-grained dense morphology, including the adhesive sublayer, AlCrN interlayer and outer layer of AlCrSiN, respectively. Fig. 2b presents nanocrystalline diffraction rings of AlCrN interlayer. The selected area electron diffraction (SAED) pattern shows CrN phase and no diffraction spots of containing aluminum phase, such as AlN phase, can be found. It can be concluded that $\mathrm{Cr}$ atoms was replaced by some $\mathrm{Al}$ atoms in the $\mathrm{CrN}$ lattice, and formed $(\mathrm{Cr}, \mathrm{Al}) \mathrm{N}$ 
solid solution in AlCrN interlayer. Fig. 2c shows the HRTEM morphology of outer layer of AlCrSiN, which exhibited superlattice structure with a modulation period of 8 nm. The high magnification morphology of AlCrSiN layer is also shown in Fig. 2c, which demonstrated that the superlattice structure consisted of alternating nanocrystalline layer and amorphous $\left(\mathrm{Si}_{3} \mathrm{~N}_{4}\right)$ layer[21].

Fig. 3 shows the SAED patterns of Al-Cr-Si-N coatings vacuum annealed at $800^{\circ} \mathrm{C}$. The SAED pattern of AlCrN interlayer is shown in Fig. 3a, which was demarcated as $\mathrm{CrN}$ and $\mathrm{Cr}_{2} \mathrm{~N}$ phases, respectively, and have an approximate crystal orientation relationship: $(00 \overrightarrow{2})_{\mathrm{CrN}} / /(0002)_{\mathrm{Cr} 2 \mathrm{~N}},[011]_{\mathrm{CrN}} / /[0110]_{\mathrm{Cr} 2 \mathrm{~N}}$ and $(02 \overrightarrow{2})_{\mathrm{CrN}} / /(\overrightarrow{2}$ 110) $\mathrm{Cr}_{\mathrm{N} N}$. It indicated that the $\mathrm{CrN}$ phases were decomposed during vacuum annealing. The SAED pattern of AlCrSiN layer(Fig.3b) identifies that the AlCrSiN layer was composed of nanocrytalline fcc-CrN phase and hcp-AlN phase. J.L. Endrino et.al[28] studied the spectral evidence of spinodal decomposition, phase transformation and molecular nitrogen formation in supersaturated TiAlN coatings upon annealing, and found that the c-AlN phase transformed into the thermodynamically more stable hcp-AlN when the vacuum annealing temperature $\geq 900{ }^{\circ} \mathrm{C}$. However, the formation temperature of hcp-AlN phase was about $800{ }^{\circ} \mathrm{C}$ in this study, this is mainly because of the influence of the Si element or superlattice structure.

Fig. 4 shows the HRTEM images of Al-Cr-Si-N coatings after vacuum annealing at $900^{\circ} \mathrm{C}$. Fig. 4a shows the cross-sectional morphologies of the coating after $900^{\circ} \mathrm{C}$ vacuum annealing. The grain boundary of AlCrSiN layer became much fuzzier compared with the as-deposited coatings. It indicated that the high enough 
temperature of vacuum annealing caused phase transformation and elemental diffusion, which damaged the superlattice microstructure of the coatings. The SAED pattern of AlCrSiN layer (Fig. 4b) confirmed the existence of pure $\alpha$-Cr phase, and this result was also supported by the XRD of Al-Cr-Si-N coatings after $900^{\circ} \mathrm{C}$ annealing, which indicated the $\mathrm{Cr}_{2} \mathrm{~N}$ phases further decomposed to $\alpha$-Cr phase during $900^{\circ} \mathrm{C}$ annealing.

\subsection{Surface morphologies}

The surface morphologies of Al-Cr-Si-N coatings before and after vacuum annealing was observed by FESEM as shown in Fig. 5. Some defects were presented on the surfaces, such as the solid or liquid particles, droplets and pinholes. These defects were typical characteristics of AIP technology. The EDS patterns indicate the particles were mainly comprised of $\mathrm{Al}, \mathrm{Cr}$ and $\mathrm{Si}$, indicating that these particles were pure Al, Cr or Al-Cr alloy. The particles were derived from the surface of the cathode material, which were local heated by the cathode spots higher power and became the molten pools. The liquid metal were sputtering deposited directly on the surface of the samples and became droplets and pinholes. Fig. 5b shows the liquid particles deposited on the coatings, which caused by the droplets shrinking. These defects easily become the channels of corrosive media, and accelerated the destruction of coatings. As shown in Fig. 5a to d, when the vacuum annealing temperatures increased from 700 to $900{ }^{\circ} \mathrm{C}$, the number and size of surface defects evidently decreased, which contributed to the pure $\mathrm{Al}$ and some Al-Cr alloy melted made the 
pinholes to be filled.

\subsection{Adhesion strength}

The Rockwell indentation and scratch test were generally accepted as two simple and effective methods in evaluating adhesion strength between coatings and substrate. The scratch test process could be divided into three stages (Lc1, Lc2, Lc3), and the load corresponding to the complete peeling of coating was termed the higher critical load Lc2, which was considered as adhesion strength of coatings[29]. Fig. 6 presents the Rockwell indentation and scratch test results of $\mathrm{Al}-\mathrm{Cr}-\mathrm{Si}-\mathrm{N}$ coatings vacuum annealed at $700{ }^{\circ} \mathrm{C}, 800{ }^{\circ} \mathrm{C}$ and $900{ }^{\circ} \mathrm{C}$, respectively. A number of cracks were discovered around the edge of the Rockwell indentation in Fig. 6a, b and d, but no chippings can be found, which indicated all the coatings exhibited good adhesion strength between the coatings and substrates. However, Fig. 6b and d had less cracks compared with Fig. 6a, and almost no cracks were found in Fig. 6c, which meant the Al-Cr-Si-N coatings annealed at $800{ }^{\circ} \mathrm{C}$ had the highest adhesion strength. The scratch test results of Al-Cr-Si-N coatings corresponding to the critical adhesive loads Lc2 in Table 2, which indicated that the adhesion strength between coatings and substrate was greatly improved with the annealing temperature increasing except the results in $900{ }^{\circ} \mathrm{C}$, and the scratch test results were extremely consistent with the results of Rockwell indentation.

As a result, the adhesion strength of coatings was greatly improved with the increasing annealing temperature owing to the reduction of residual stress and 
structural defects[16]. However, when the annealing temperature reached $900{ }^{\circ} \mathrm{C}$, the critical load Lc2 decreased, It mainly caused by the formation of negative $\sigma-\mathrm{FeCr}$ phases, and the $\sigma$-FeCr phases were hard and fragile, which could decrease the ductility of coatings[30].

\subsection{Electrochemical performance}

Fig. 7 shows the potentiodynamic polarisation curves of the Al-Cr-Si-N coatings before and after vacuum annealing in $3.5 \% \mathrm{NaCl}$ solution. The corrosion potential $\left(\boldsymbol{E}_{\text {corr }}, \mathrm{V}\right)$, the corrosion current $\left(\boldsymbol{i}_{\text {corr }}, \mathrm{A} . \mathrm{cm}^{-2}\right)$ and the polarisation resistance $\left(\boldsymbol{R}_{\boldsymbol{p}}, \Omega . \mathrm{cm}^{2}\right)$ were obtained from these curves are displayed in Table 3. The $\boldsymbol{E}_{\text {corr }}$ of as-deposited coatings was about $-0.238 \mathrm{~V}$, and the $\boldsymbol{i}_{\text {corr }}$ was about $2.787 \times 10^{-8} \mathrm{~A} . \mathrm{cm}^{-2}$. After $700{ }^{\circ} \mathrm{C}$ vacuum annealing, the $\boldsymbol{E}_{\text {corr }}$ of coatings increased to $-0.178 \mathrm{~V}$, and the $\boldsymbol{i}_{\text {corr }}$ decreased to $5.438 \times 10^{-9}$ A.cm ${ }^{-2}$. Similarly, the $\boldsymbol{E}_{\text {corr }}$ of coatings increased to $0.045 \mathrm{~V}$ after $800{ }^{\circ} \mathrm{C}$ vacuum annealing, and the $\boldsymbol{i}_{\text {corr }}$ decreased to $8.805 \times 10^{-10}$ A.cm ${ }^{-2}$. However, the $\boldsymbol{E}_{\text {corr }}$ of coatings annealed at $900{ }^{\circ} \mathrm{C}$ was lower than $800{ }^{\circ} \mathrm{C}$, but still shifted toward more positive than others, which indicated the corrosion resistance of the coatings was greatly improved after vacuum annealing, and the $800^{\circ} \mathrm{C}$ annealed coatings had the best corrosion resistant properties.

$\boldsymbol{P ( \% )}$ (Table 3)was obtained by the following equation[31], which represented the protective efficiency, and calculated from the potentiodynamic polarisation data.

$$
\mathrm{P}(\%)=\left(1-\mathrm{i}_{\text {corr }} / \mathrm{i}_{\text {corr }}^{0}\right) \times 100 \%
$$

Where $\boldsymbol{i}_{\text {corr }}$ and $\boldsymbol{i}_{\text {corr }}^{0}$ denoted the corrosion current densities of the bare and 
covered electrodes, respectively. As listed in Table 3, with the increasing annealing temperature, the protective efficiency was $84.53 \%, 97.50 \%$ and $97.07 \%$, respectively. The $800{ }^{\circ} \mathrm{C}$ annealed sample had the highest $\boldsymbol{P ( \% )}$ in $3.5 \% \mathrm{NaCl}$ solution.

Similarly, Fig. 8 shows the potentiodynamic polarisation curves of the Al-Cr-Si-N coatings before and after vacuum annealing in $10 \% \mathrm{H}_{2} \mathrm{SO}_{4}$ solution, and the corresponding corrosion parameters are listed in Table 4. It was obvious that the $\boldsymbol{E}_{\text {corr }}$ of coatings annealed at $700{ }^{\circ} \mathrm{C}$ was more positive than coatings in other conditions. The corresponding $\boldsymbol{i}_{\text {corr }}$ decreased about four orders of magnitude compared with as-deposited coatings, and the $\boldsymbol{P ( \% )}$ was the highest, which indicated the coatings had the best corrosion resistance in acid environment after $700{ }^{\circ} \mathrm{C}$ annealing.

In short, the corrosion resistance of the nano-composite Al-Cr-Si-N coatings were improved obviously after vacuum annealing at various temperatures. The number and size of surface defects evidently decreased when vacuum annealing temperatures increased from $700^{\circ} \mathrm{C}$ to $900{ }^{\circ} \mathrm{C}$, which could be considered as one of the reasons to improved the corrosion resistance of the coatings. The difference in the corrosion resistance of the coatings were also related to the microstructure variation of coatings. The Si element was mainly existed in the form of amorphous $\mathrm{Si}_{3} \mathrm{~N}_{4}$, which were proved in the analysis of HRTEM. The amorphous $\mathrm{Si}_{3} \mathrm{~N}_{4}$ had very good corrosion resistance owing to its dielectric nature and dense microstructure without preferential corrosion paths like grain boundaries and other structural defects. Moreover, the addition of $\mathrm{Si}_{3} \mathrm{~N}_{4}$ could decrease the crystallite size and enhance the 
dense of coatings microstructure[32]. On the other hand, the coatings showed nano-multilayer superlattice structure, which blocked the path of corrosion medium. Therefore, the as-deposited coatings exhibited good corrosion resistance. When the vacuum annealing temperatures reached $700{ }^{\circ} \mathrm{C}$, the coatings were given priority to hcp-AlN and $\mathrm{Cr}_{2} \mathrm{~N}$ ceramic phases, which were believed to be responsible for the enhanced corrosion behavior compared with the as-deposited coatings. After $800^{\circ} \mathrm{C}$ vacuum annealing, the coatings mainly existed as hcp-AlN, $\mathrm{CrN}, \mathrm{Cr}_{2} \mathrm{~N}$ and a small amount of $\alpha$-Cr phases. The $\alpha$-Cr and $\mathrm{CrN}$ phases also had good corrosion resistance in $\mathrm{NaCl}$ aqueous solution. Whereas, Masami Taguchi et al.[33] reported that the pure $\mathrm{Cr}$, mixtures of $\alpha-\mathrm{Cr}+\mathrm{Cr}_{2} \mathrm{~N}$ were rapidly attacked in $10 \mathrm{wt} \% \mathrm{H}_{2} \mathrm{SO}_{4}$ solution, and in a mixture of $\mathrm{Cr}_{2} \mathrm{~N}+\mathrm{CrN}, \mathrm{Cr}_{2} \mathrm{~N}$ was selectively corroded. Therefore, the corrosion resistance of the coatings annealed at $800^{\circ} \mathrm{C}$ were further enhanced in $3.5 \% \mathrm{NaCl}$ solution, but reduced in $10 \% \mathrm{H}_{2} \mathrm{SO}_{4}$ solution. However, the $\sigma$-FeCr phases were detected in the coatings annealed at $900^{\circ} \mathrm{C}$, which easily produced a significant corrosion attack[34]. Meanwhile, the superlattice microstructure of the AlCrSiN coatings was damaged during $900^{\circ} \mathrm{C}$ annealing, which was greatly affected the corrosion resistance of the coatings. Hence, the corrosion potential of coatings were more negative, and the corrosion resistance of coatings were farther decreased.

\section{Conclusions}

In this study, the microstructures, surface morphologies, adhesion strength and corrosion resistance of the nano-composite Al-Cr-Si-N coatings annealed at different 
temperatures were investigated. The as-deposited coatings mainly composed of the solid solution (Al,Cr)N. With increasing annealing temperature, the solid solution (Al,Cr)N decomposed into $\mathrm{CrN}, \mathrm{Cr}_{2} \mathrm{~N}$ and hcp-AlN phases, and then the $\mathrm{CrN}$ phase further decomposed into $\mathrm{Cr}_{2} \mathrm{~N}$ and $\mathrm{Cr}$ With $\mathrm{N}_{2}$. Then the $\mathrm{Cr}$ atoms formed $\sigma-\mathrm{FeCr}$ with Fe atoms which spread into substrates. Superlattice structure appeared in the nano-composite $\mathrm{Al}-\mathrm{Cr}-\mathrm{Si}-\mathrm{N}$ coatings, and the Si element mainly existed in the form of amorphous $\mathrm{Si}_{3} \mathrm{~N}_{4}$. But the superlattice structure was damaged after $900{ }^{\circ} \mathrm{C}$ annealing. With the increasing annealing temperature, the number and size of some defects gradually decreased in the nano-composite Al-Cr-Si-N coatings. The Rockwell indentation and scratch tests indicated that the coatings annealed at $800{ }^{\circ} \mathrm{C}$ had the best adhesion strength between coatings and substrates among all series. Because of structural optimisation and improvement on surface defects and interface adhesion, the corrosion resistance of annealed coatings were better than SS316L, and coating annealed at $800^{\circ} \mathrm{C}$ had the best corrosion resistance in $3.5 \% \mathrm{NaCl}$ solution. When the corrosion medium was $10 \% \mathrm{H}_{2} \mathrm{SO}_{4}$ solution, the coatings annealed at $700^{\circ} \mathrm{C}$ had the best corrosion resistance.

\section{Acknowledgments:}

This work was supported by the National Science Foundation of China (No. 51305002), International Science \& Technology Cooperation Program of China (No. 2014DFG72720) and the Science Foundation of Anhui Province (No. 1408085QE92).

\section{References}


[1] J.L. Endrino, G.S. Fox-Rabinovich, C. Gey, Hard AlTiN, AlCrN PVD coatings for machining of austenitic stainless steel, Surf. Coat. Technol. 200 (2006) 6840-6845.

[2] E. Le Bourhis, P. Goudeau, M. Staia, E. Carrasquero, E. Puchi-Cabrera, Mechanical properties of hard AlCrN-based coated substrates, Surf. Coat. Technol. 203 (2009) 2961-2968.

[3] J. Park, Y. Baik, The crystalline structure, hardness and thermal stability of AlN/CrN superlattice coating prepared by D.C. magnetron sputtering, Surf. Coat. Technol. 200 (2005) 1519-1523.

[4] N. Beliardouh, K. Bouzid, C. Nouveau, B. Tlili, M. Walock, Tribological and electrochemical performances of $\mathrm{Cr} / \mathrm{CrN}$ and $\mathrm{Cr} / \mathrm{CrN} / \mathrm{CrAlN}$ multilayer coatings deposited by RF magnetron sputtering, Tribol. Int. 82 (2015) 443-452.

[5] M. Hua, H. Ma, C. Moka, J. Li, Tribological behavior of patterned PVD TiN coatings on M2 steel, Tribol. Lett. 17 (2004) 645-653.

[6] Y. Feng, L. Zhang, R. Ke, Q. Wan, Z. Wang, Z. Lu, Thermal stability and oxidation behavior of AlTiN, AlCrN and AlCrSiWN coatings, Int. J. Refract. Met. Hard Mater. 43 (2014) 241-249.

[7] Z. Zhou, P. Tam, P. Shum, K. Li, High temperature oxidation of CrTiAlN hard coatings prepared by unbalanced magnetron sputtering, Thin Solid Films 517 (2009) $5243-5247$.

[8] S. Zhang, L. Wang, Q. Wang, M. Li, A superhard CrAlSiN superlattice coating deposited by a multi-arc ion plating: II. Thermal stability and oxidation resistance, Surf. Coat. Technol. 214 (2013) 153-159. 
[9] C. Chang, J. Lee, M. Tseng, Microstructure, corrosion and tribological behaviors of TiAlSiN coatings deposited by cathodic arc plasma deposition, Thin Solid Films 517 (2009) 5231-5236.

[10] F. Cai, Q. Yang, X. Huang, R. Wei, Microstructure and corrosion behavior of CrN and CrSiCN coatings, J. Mater. Eng. Perform. 19 (2010) 721-727.

[11] H. Feng, C. Hsu, J. Lu, Y. Shy, Effects of PVD sputtered coatings on the corrosion resistance of AISI 304 stainless steel, Mater. Sci. Eng. A. 347 (2003) $123-129$.

[12] P. Panjan, P. Gselman, D. Kek-Merl, M. Čekada, M. Panjan, G. Dražić, T. Bončina, F. Zupanič, Growth defect density in PVD hard coatings prepared by different deposition techniques, Surf. Coat. Technol. 237 (2013) 349-356.

[13] L. Cunha, M. Andritschky, Residual stress, surface defects and corrosion resistance of CrN hard coatings, Surf. Coat. Technol. 111 (1999) 158-162.

[14] C. Petrogalli, L. Montesano, M. Gelfi, G.M. La Vecchia, L. Solazzi, Tribological and corrosion behavior of CrN coatings: Roles of substrate and deposition defects, Surf. Coat. Technol. 258 (2014) 878-885.

[15] C. Liu, A. Leyland, Q. Bi, A. Matthews, Corrosion resistance of multi-layered plasma-assisted physical vapour deposition TiN and CrN coatings, Surf. Coat. Technol. 141 (2001) 164-173.

[16] M. S. Ahmed, P. Munroe, Z. Jiang, X. Zhao, W. Rickard, Z. Zhou, L. Li, Z. Xie, Corrosion behaviour of nanocomposite TiSiN coatings on steel substrates, Corros. Sci. 53 (2011) 3678-3687. 
[17] C. Chang, W. Chen, P. Tsai, W. Ho, D. Wang, Characteristics and performance of TiSiN/TiAlN multilayers coating synthesized by cathodic arc plasma evaporation, Surf. Coat. Technol. 202 (2007) 987-992.

[18] S. Tsai, J. Duh, Microstructure and corrosion properties of multilayered CrAlN/SiN ${ }_{x}$ coatings, J. Electrochem. Soc., 157 (2010) 89-95.

[19] M. Ibrahim, S. Korablov, M. Yoshimura, Corrosion of stainless steel coated with TiN, (TiAl)N and CrN in aqueous environments, Corros. Sci. 44 (2002) 815-828.

[20] S. Zhang, L. Wang, Q. Wang, M. Li, A superhard CrAlSiN superlattice coating deposited by multi-arc ion plating: I. Microstructure and mechanical properties, Surf. Coat. Technol. 214 (2013) 160-167.

[21] W. Wu, W. Chen, S. Yang, Y. Lin, S. Zhang, T. Cho, G. Lee, S. Kwon, Design of AlCrSiN multilayers and nanocomposite coating for HSS cutting tools, Appl. Surf. Sci. 351 (2015) 803-810.

[22] D. Lee, T. Nguyen, S. Kim, Air-oxidation of nano-multilayered CrAlSiN thin films between 800 and $1000{ }^{\circ} \mathrm{C}$, Surf. Coat. Technol. 203 (2009) 1199-1204.

[23] J. Soldán, J. Neidhardt, B. Sartory, R. Kaindl, R. Čerstvý, P.H. Mayrhofer, R. Tessadri, P. Polcik, M. Lechthaler, C. Mitterer, Structure-property relations of arc-evaporated Al-Cr-Si-N coatings, Surf. Coat. Technol. 202 (2008) 3555-3562.

[24] T. Polcar, A. Cavaleiro, High temperature properties of CrAlN, CrAlSiN and AlCrSiN coatings - Structure and oxidation, Mater. Chem. Phys. 129 (2011) 195-201. [25] C. Lin, J. Duh, Electrochemical impedance spectroscopy (EIS) study on corrosion performance of CrAlSiN coated steels in 3.5 wt.\% NaCl solution, Surf. Coat. 
Technol. 204 (2009) 784-787.

[26] H. Willmann, P.H. Mayrhofer, P.O.A. Persson, A. Reiter, L. Hultman, C. Mitterer, Thermal stability of Al-Cr-N hard coatings, Scripta Mater. 54 (2006) 1847-1851.

[27] X. Pang, H. Yang, X. Liu, K. Gao, Y. Wang, A. Volinsky, A. Levin, Annealing effects on microstructure and mechanical properties of sputtered multilayer $\mathrm{Cr}_{(1-}$ x) $\mathrm{Al}_{\mathrm{x}} \mathrm{N}$ films, Thin Solid Films 519 (2011) 5831-5837.

[28] J. Endrino, C. Arhammar, A. Gutierrez, R. Gago, D. Horwat, L. Soriano, G. Fox-Rabinovich, D. Martin y Marero, J. Guo, J. Rubensson, J. Andersson, Spectral evidence of spinodal decomposition, phase transformation and molecular nitrogen formation in supersaturated TiAlN films upon annealing, Acta Mater. 59 (2011) $6287-6296$.

[29] S. Zhang, D. Sun, Y. Fu, H. Du, Toughness measurement of thin films: a critical review, Surf. Coat. Technol. 198 (2005) 74-84.

[30] M. H. Bina, Study on formation and morphology of sigma-phase in continuous annealing furnace roller, Eng. Fail. Anal. 34 (2013) 174-180.

[31] N. Nam, M. Vaka, N. Hung, Corrosion behavior of TiN, TiAlN, TiAlSiN-coated 316L stainless steel in simulated proton exchange membrane fuel cell environment, J. Power Sources 268 (2014) 240-245.

[32] V. Selvi, V.K. Grips, H. Barshilia, Electrochemical behavior of superhard nanocomposite coatings of $\mathrm{TiN} / \mathrm{Si}_{3} \mathrm{~N}_{4}$ prepared by reactive DC unbalanced magnetron sputtering, Surf. Coat. Technol. 224 (2013) 42-48.

[33] M. Taguchi, H. Takahashi, Corrosion behavior of chromium nitride coatings 
produced by reactive ion plating in sulfuric acid solution, Mater. Trans. 35 (1994) 356-362.

[34] O. Conejero, M. Palacios, S. Rivera, Premature corrosion failure of a 316L stainless steel plate due to the presence of sigma phase, Eng. Fail. Anal. 16 (2009) 699-704. 


\section{Figure captions}

Figure 1 XRD diffraction patterns of as-deposited AlCrSiN coatings and vacuum annealed coatings at temperatures of $700{ }^{\circ} \mathrm{C}, 800^{\circ} \mathrm{C}$ and $900^{\circ} \mathrm{C}$.

Figure 2 The HRTEM images of as-deposited AlCrSiN coatings: (a) Cross-sectional morphologies image, (b) The SAED pattern of AlCrN interlayer, (c)High resolution morphologies.

Figure 3 The SAED patterns of AlCrSiN coatings vacuum annealed at $800^{\circ} \mathrm{C}$ : (a) The SAED pattern of AlCrN interlayer; (b) The SAED pattern of AlCrSiN layer.

Figure 4 The HRTEM images of $900^{\circ} \mathrm{C}$ annealed AlCrSiN coatings: (a) High resolution morphologies; (b) The SAED pattern of AlCrSiN layer.

Figure 5 Surface FESEM micrographs of as-deposited AlCrSiN films (a), and coatings after vacuum annealed at temperatures of $700{ }^{\circ} \mathrm{C}$ (b), $800{ }^{\circ} \mathrm{C}$ (c) and $900{ }^{\circ} \mathrm{C}$ (d).

Figure 6 The Rockwell indentation and scratch test results of AlCrSiN coatings vacuum annealed at temperatures of $700{ }^{\circ} \mathrm{C}, 800{ }^{\circ} \mathrm{C}$ and $900{ }^{\circ} \mathrm{C}$.

Figure 7 Potentiodynamic polarisation curves of the AlCrSiN coatings before and after vacuum annealing in $3.5 \mathrm{wt} \% \mathrm{NaCl}$ solution.

Figure 8 Potentiodynamic polarisation curves of the $\mathrm{AlCrSiN}$ coatings before and after vacuum annealing in $10 \mathrm{wt} \% \mathrm{H}_{2} \mathrm{SO}_{4}$ solution. 
Table 1

Deposition parameters on each layer of the AlCrSiN coatings.

\begin{tabular}{cccc}
\hline Various deposition parameters & CrN layer & AlCrN layer & AlCrSiN layer \\
\hline Nitrogen flow rates (sccm) & 800 & 900 & 900 \\
Vacuum pressure(pa) & 0.8 & 1.5 & 2 \\
Temperature $\left({ }^{\circ} \mathrm{C}\right)$ & 450 & 450 & 450 \\
Arc current of Cr cathode (A) & 60 & 60 & - \\
Arc current of AlCr cathode (A) & - & 65 & 75 \\
Arc current of AlCrSi cathode (A) & - & - & 75 \\
Bias voltage (V) & 120 & 80 & 80 \\
Time(s) & 960 & 7200 & 9000 \\
\hline
\end{tabular}


Table 2

The critical adhesive loads $\mathrm{Lc} 2$ of $\mathrm{AlCrSiN}$ coatings annealed at various temperatures.

\begin{tabular}{ccccc}
\hline Temperatures $\left({ }^{\circ} \mathrm{C}\right)$ & As-deposited & 700 & 800 & 900 \\
\cline { 1 - 1 } Lc2 $(\mathrm{N})$ & 28.7 & 40.5 & 53.2 & 40.8 \\
\hline
\end{tabular}


Table 3

Potentiodynamic polarisation data of the ss $316 \mathrm{~L}$ and $\mathrm{AlCrSiN}$ coatings before and after vacuum annealing in $3.5 \mathrm{wt} \% \mathrm{NaCl}$ solution

\begin{tabular}{ccccc}
\hline Specimen & $\begin{array}{c}\mathbf{E}_{\text {corr }} \\
\mathbf{( V )}\end{array}$ & $\begin{array}{c}\mathbf{i}_{\text {corr }} \\
\mathbf{( A . \mathbf { c m } ^ { - 2 } )}\end{array}$ & $\begin{array}{c}\mathbf{R}_{\mathbf{p}} \\
\mathbf{( \mathbf { \Omega . c m } ^ { 2 } )}\end{array}$ & $\mathbf{P ( \% )}$ \\
\hline SS316L & -0.356 & $3.52 \times 10^{-8}$ & $1.19 \times 10^{6}$ & - \\
As-deposited & -0.238 & $2.79 \times 10^{-8}$ & $7.68 \times 10^{5}$ & 20.73 \\
$700^{\circ} \mathrm{C}$ & -0.178 & $5.44 \times 10^{-9}$ & $5.30 \times 10^{6}$ & 84.53 \\
$800^{\circ} \mathrm{C}$ & 0.045 & $8.81 \times 10^{-10}$ & $4.07 \times 10^{7}$ & 97.50 \\
$900^{\circ} \mathrm{C}$ & -0.151 & $1.02 \times 10^{-9}$ & $3.62 \times 10^{7}$ & 97.07 \\
\hline
\end{tabular}


Table 4

Potentiodynamic polarisation data of the ss $316 \mathrm{~L}$ and $\mathrm{AlCrSiN}$ coatings before and after vacuum annealing in $10 \mathrm{wt} \% \mathrm{H}_{2} \mathrm{SO}_{4}$ solution

\begin{tabular}{ccccc}
\hline Specimen & $\begin{array}{c}\mathbf{E}_{\text {corr }} \\
\mathbf{( V )}\end{array}$ & $\begin{array}{c}\mathbf{i}_{\text {corr }} \\
\left(\mathbf{A . c c ^ { - 2 }}\right)\end{array}$ & $\begin{array}{c}\mathbf{R}_{\mathbf{p}} \\
\left(\mathbf{\Omega . c \mathbf { c m } ^ { 2 }}\right)\end{array}$ & $\mathbf{P ( \% )}$ \\
\hline SS316L & -0.085 & $7.174 \times 10^{-5}$ & $6.84 \times 10^{2}$ & - \\
As-deposited & 0.005 & $7.608 \times 10^{-6}$ & $3.16 \times 10^{3}$ & 89.4 \\
$700^{\circ} \mathrm{C}$ & 0.222 & $6.04 \times 10^{-9}$ & $6.63 \times 10^{6}$ & 99.99 \\
$800^{\circ} \mathrm{C}$ & 0.054 & $3.691 \times 10^{-8}$ & $1.09 \times 10^{5}$ & 99.95 \\
$900^{\circ} \mathrm{C}$ & 0.016 & $1.944 \times 10^{-6}$ & $2.06 \times 10^{4}$ & 97.29 \\
\hline
\end{tabular}


Figure 2
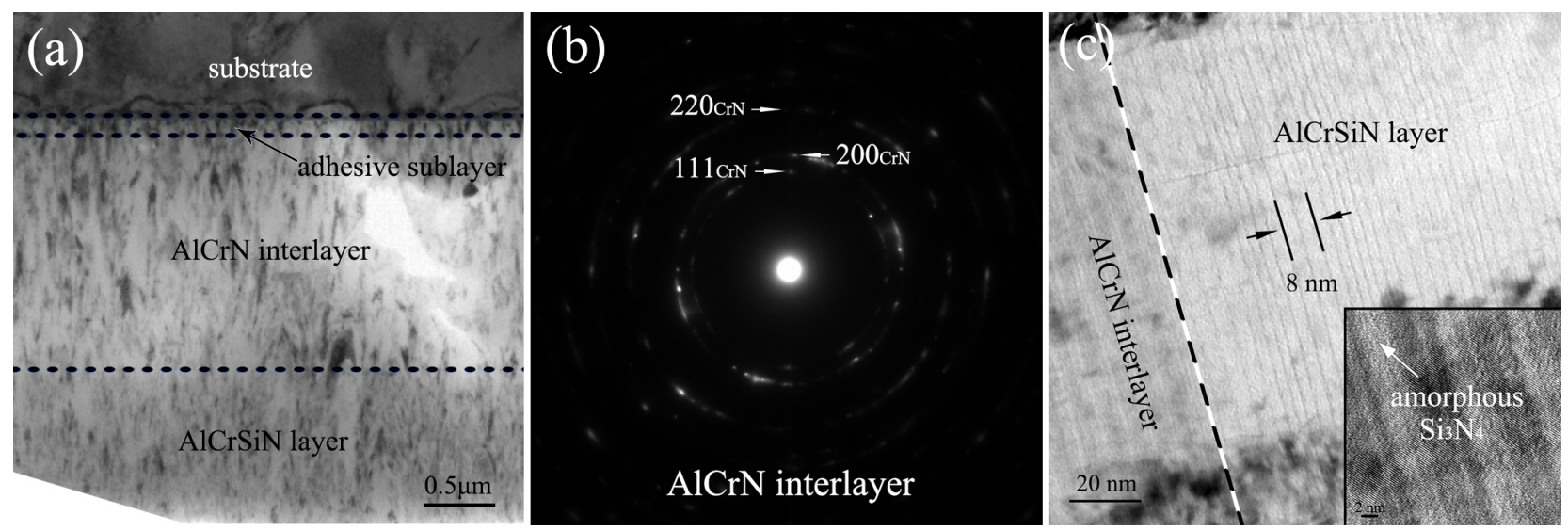
Figure 3

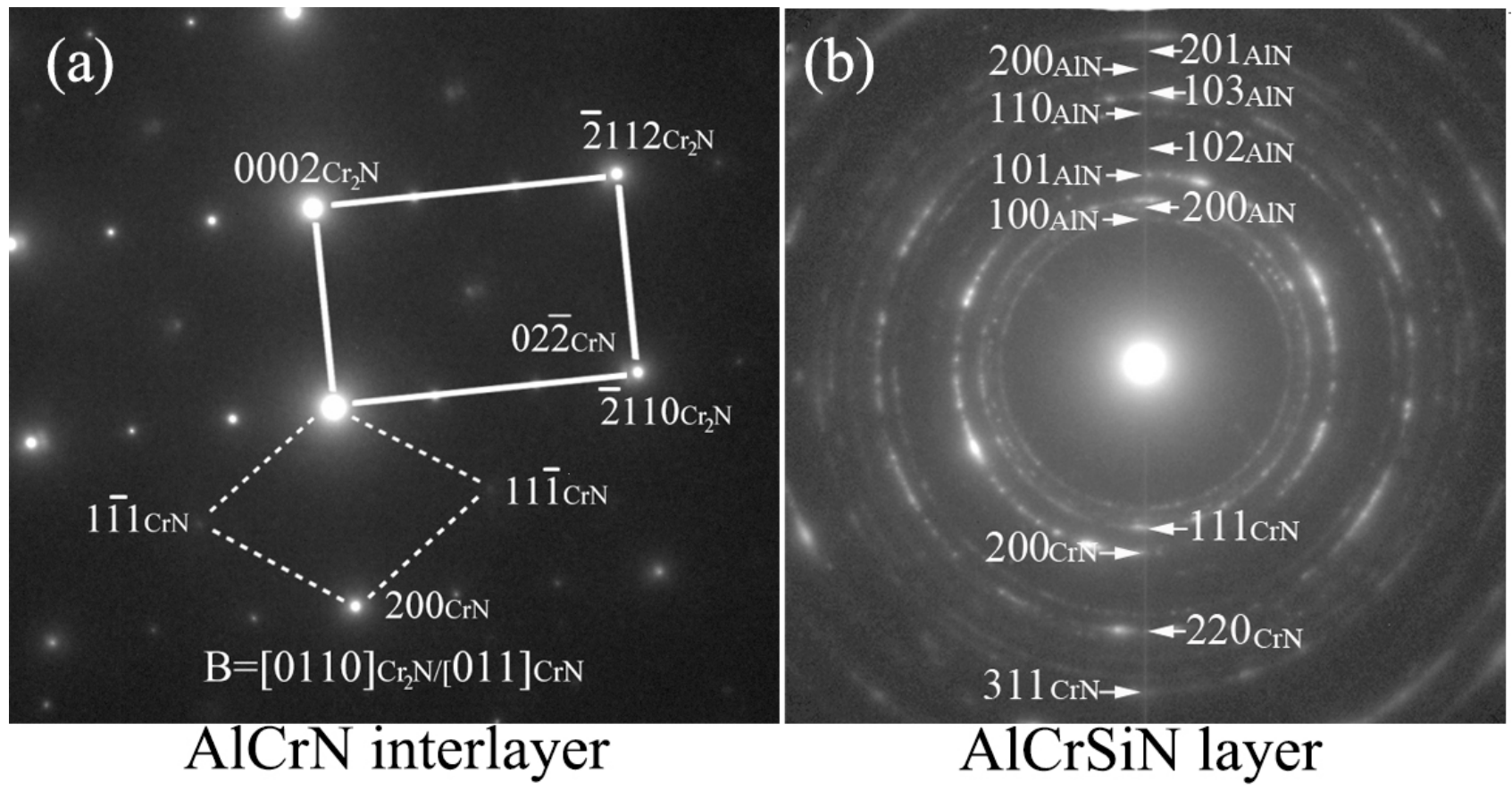


Figure 4

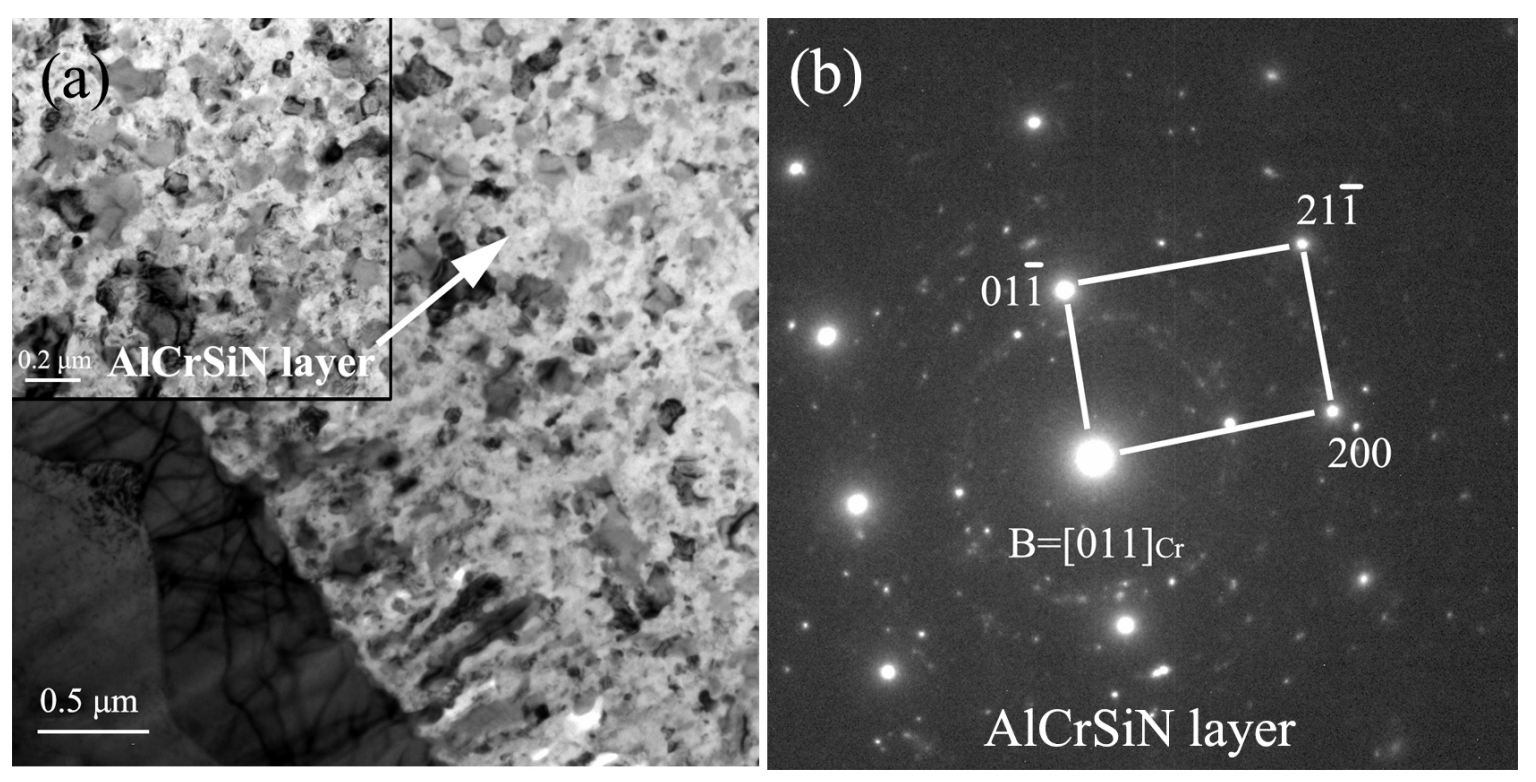


Figure 5

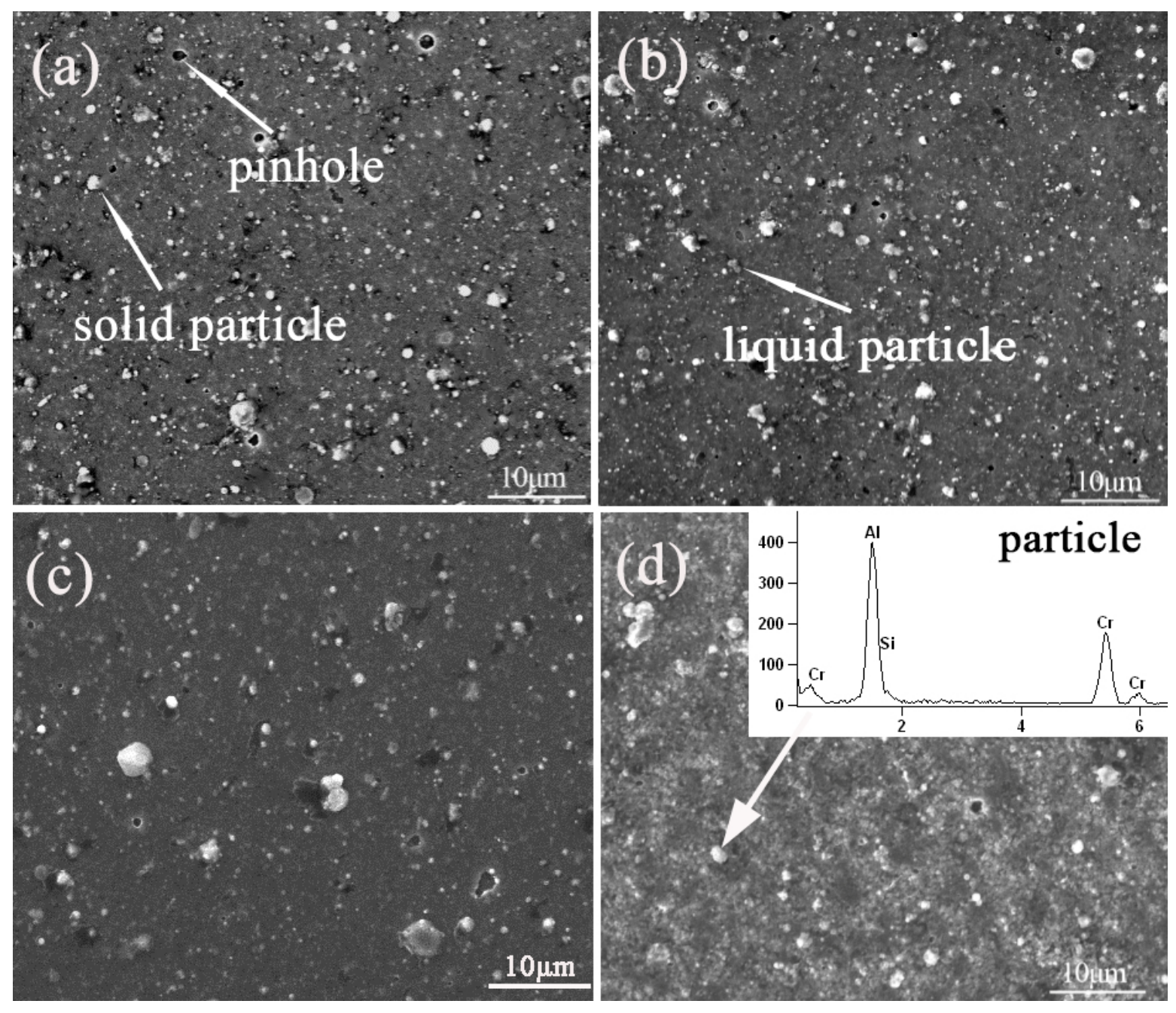




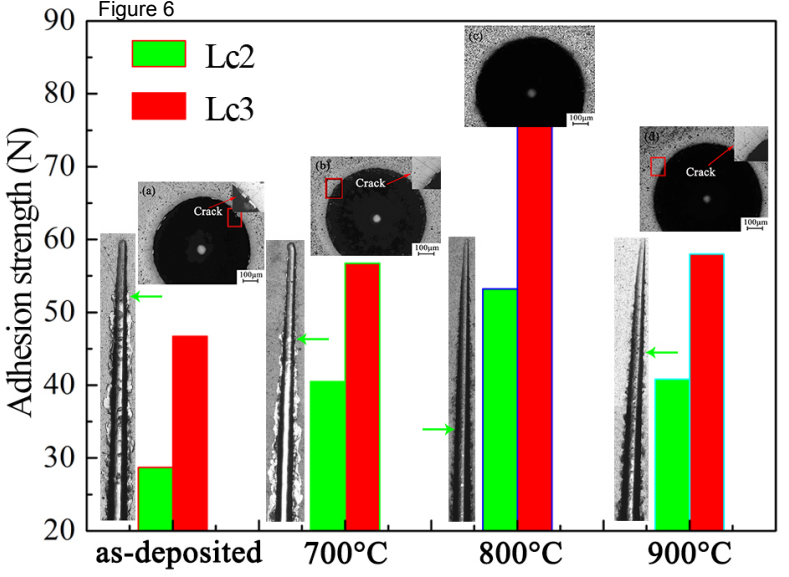




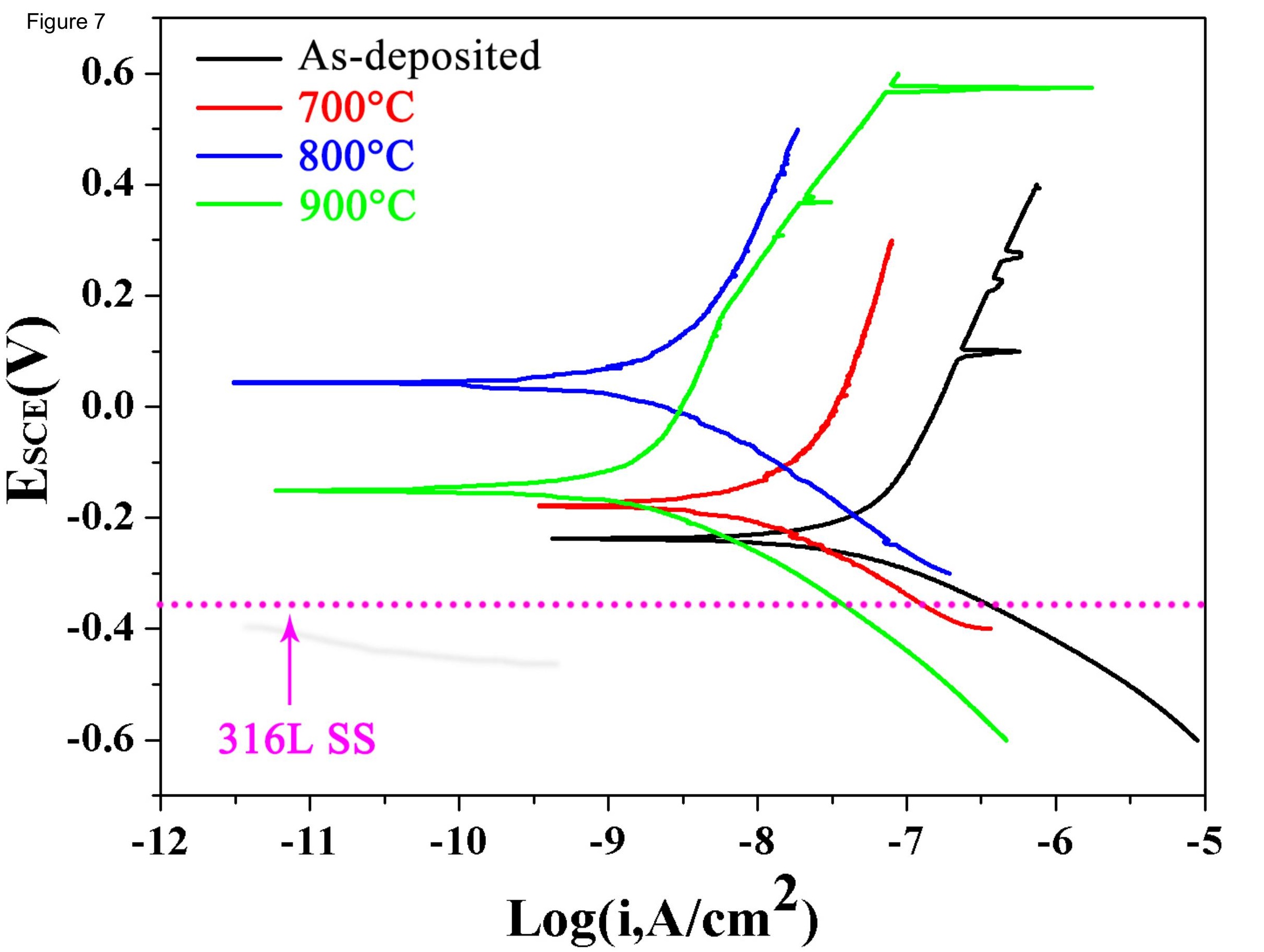


